\title{
11 Approaches for Attracting, Retaining, and Progressing Women in Australian Undergraduate Engineering
}

\author{
Curricular Innovation Focused on \\ Humanitarian and Human-Centered \\ Design Concepts
}

\author{
Andrea M. Goncher and Shara Cameron
}

Education sectors across the world have invested in programs to widen participation in order to increase student diversity in the STEM degrees and careers (Education Services Australia, 2018; Berge, Silfver, \& Danielsson, 2018). Increasing the participation of women in STEM degrees and professions is a high priority for Australian universities, industry, and government. Despite national efforts, university engineering programs have faced challenges that include student retention and diversity within student and faculty populations (Cross et al., 2017). Reports conducted by the government, industry, and education sectors show recent trends of women's participation declining in the engineering industry and degree completion (Office of the Chief Scientist, 2016; Australian Academy of Sciences, 2019; Engineering for Australia Taskforce, 2020). The Australian Government, various Australian universities, and professional organizations have dedicated programs and initiatives for women in engineering (and STEM), contributing to a slow upward trend of women commencing engineering degrees (Corrigan \& Aikens, 2020).

The purpose of this chapter is to examine government-supported programs, university and industry partnerships, and inclusive engineering design programs to promote gender diversity in Australia. We describe example programs focused on attracting, supporting, and retaining women in engineering, e.g., engineering experiences for students in high school years nine and ten, curricular and co-curricular human-centered design experiences, inclusive engineering program design, and industry mentoring. We also include an example learning activity in human-centered design that educators can use to encourage women's participation in engineering and link the curriculum to engineering practice and potential future career applications. We chose these programs to show how faculty involvement (particularly by women professors) and diverse pedagogies can encourage women students to choose and complete their

DOI: $10.4324 / 9781003053217-2$ 
degrees in engineering. For example, women students are inspired to pursue STEM fields based on the relevance of STEM in their lives as well as exposure to female role models (Education Services Australia, 2018). In this chapter, we highlight important issues in attracting, retaining, and progressing women in engineering, as well as provide information that will help to support engineering educators in secondary, tertiary, and industry education.

\section{Contexts}

\section{Higher Education in Australia}

The Australian higher education system consists of 140 institutions in three major classifications: public $(\mathrm{N}=38)$, private $(\mathrm{N}=10)$, and other approved higher education institutions $(\mathrm{N}=92)$ (Department of Education, Skills, and Employment, 2020). The domestic student load for women and men in public universities was not extremely disparate during the period from 2015 to 2019. Female enrollment is slightly higher than male enrollment overall for university degrees (Higher Education Data Cube, 2020).

Participation in higher education has increased over the last two decades and international student enrollment has increased significantly since 2001 (Graham, 2018). Australia's unique higher education landscape includes its international education sector as one of Australia's top three exports (Department of Education and Training, 2018). While participation has increased, an imbalance in representation still challenges the STEM sector. A gender gap exists in Australian STEM education participation, with especially low participation from students from rural and regional areas and Aboriginal and Torres Strait Islander backgrounds. Australia has embraced the demand for a STEM-skilled workforce, realizing the importance of gender equity and the role of tertiary education in enabling women, including those from disadvantaged backgrounds, to be successful in these careers (Australian Academy of Science, 2019).

\section{STEM Enrollment in Australian Universities}

The Federal Government's Women in STEM Decadal Plan provides motivation for collaboration across the university sector, together with industry and schools, to broaden and deepen the impact on girls and women pursuing engineering studies (Australian Academy of Science, 2019). The creation of this plan recognizes the previous trends on women's participation in STEM and further advances women's participation in STEM fields. The number of women enrolled in university STEM courses increased between 2015 and 2018, however, men were enrolling in STEM programs at an almost proportional rate.

The situation is similar for data regarding STEM university qualification completions. More women and men are completing university STEM qualifications since 2015. The impact of women's underrepresentation in undergraduate 
STEM programs carries forward to women being under-represented in STEM careers and negatively couples with other factors such as workplace culture discrimination and bias and lack of work options and career progression opportunities (Australian Academy of Science, 2019).

Within STEM, women are particularly under-represented in engineering. Women in Australia make up $17 \%$ of university enrollments in engineering (Australian Academy of Science, 2019). Similarly, women only make up 12\% of the engineering workforce (Kaspura, 2019). Women typically earn less than their male counterparts, represented by an $16.7 \%$ pay gap in engineering (Australian Academy of Science, 2019, p. 7). Australia's national gender pay gap was $13.4 \%$ across all industries and has fluctuated between $13.4 \%$ and 18.5\% within the past 20 years (Workplace Gender Equality Agency, 2020).

\section{Professional Associations for Women in Engineering}

Engineers Australia (EA) is the national body for professional engineers with over 100,000 members across engineering disciplines. EA is also the accrediting body for engineering degree programs granting professional status to graduates within Australia and the international Washington Accord agreement (Howard \& Campbell, 2013). As of December 2020, EA listed 53 institutions with accredited engineering programs (EA, December 2020). Programs in various engineering disciplines are accredited at the Professional Engineer, Engineering Technologist, and Engineering Associate levels.

The relationship and interactions across the engineering professional body, accrediting agency, universities, and educators in Australia is rather uncommon in engineering education (Brodie \& Bullen, 2013; Howard \& Campbell, 2013). Engineers Australia, the Australian Council for Engineering Deans (ACED), and the Australasian Association for Engineering Education (AAEE) engage in partnerships and have connections to the university system. Through partnerships and analyses of the Australian engineering and education sectors, these organizations have produced comprehensive reports on these sectors and on the intersection of sectors (ACED, 2016). ACED has produced position statements specifically addressing the role of the mathematics requirements in secondary school for enrollment and participation in engineering education (ACED, 2019), developing engineering graduates engineers equipped to work in complex contexts through incorporating humanitarian engineering principles into the curriculum (2018), and increasing the participation of Indigenous people (ACED, 2017a) and women in engineering (ACED, 2017b). The Australian Council for Engineering Deans' identification of contemporary issues challenging the engineering sector, which includes increasing representation and participation of women in engineering, is important to increasing visibility within and outside of the profession and ultimately improving experiences for women in engineering.

To address the underrepresentation of women in Australian engineering, we review examples of programs and initiatives that support women in engineering based on EA reports as well as peer-reviewed research in the 
engineering education field. The examples presented in this chapter promote the attraction, retention, and progression of women in engineering at the undergraduate level. We structure the examples under three main recommendations: 1) Recruiting and supporting women students, 2) Recruiting and supporting women [academic] staff, and 3) Improving the curriculum (ACED, 2017b).

\section{Programs and Initiatives Focused on Women in Undergraduate Engineering Education}

The ACED position paper (2017b) on increasing women's participation in engineering presents three main recommendations: 1) Recruiting and supporting women students, 2) Recruiting and supporting women [academic] staff, and 3) Improving the Curriculum. In this section we provide examples of programs and initiatives that relate, align, and support the ACED's three recommendations for action. However, the programs and initiatives discussed in this report are not a comprehensive list of existing Women in engineering (WIE) structures, programs, initiatives, or other frameworks to support undergraduate women in engineering. The programs and initiatives presented in the following sections have national engagement either through universities and/or high schools, or have activities, outreach, or initiatives within the program that align approaches for attracting, retaining, and supporting women students and faculty.

\section{Recruiting and Supporting Women Students}

Increasing the participation of women in engineering through university-based and other outreach programs not only helps to provide support and networking systems for women students currently studying engineering, it also helps in the recruitment of prospective students. Australian universities typically have a WIE group that recruits and supports women students through different initiatives, programs, and foci. One example of a WIE university program is Fifty 50 at the Australian National University (ANU) (Fifty50, n.d.). Fifty50 is a student-led organization designed to narrow the gender gap in STEM fields through various programs, including mentoring (and increasing the visibility of such role models), engaging in the wider STEM community (the organization includes women students in science, technology, and mathematics), and advocating for policy change. The organization runs frequent events aimed at supporting equitable pathways through engineering into industry, which are open to students of all genders at ANU. These events offer notable additions to the standard curriculum through 1) short courses on programming languages and other technical content, 2) professional development help such as seminars on interview preparation, managing your online presence and LinkedIn, networking events aimed at creating mentoring-type connections between current students and alumni and professionals across fields, and 3) industry panels and networking events across STEM fields. 
In addition to live events for ANU undergraduate students, the Fifty50 website also hosts articles related to the initiatives that are offered live, as well as an ongoing blog, mentor facilitation, and a podcast to help reach out to the community beyond ANU. There is also a space to inquire about where to start and members are on hand to direct potential members to a constructive starting point for their STEM interests. Fifty50 has multiple coordinated programs, events, and initiatives that engage various stakeholders and align with the recommended program-level approach for shifting barriers for women students in STEM fields (Australian Academy of Science, 2019).

Another organization that brings together undergraduate engineering students, faculty, and industry volunteers is Power of Engineering Inc ( $\mathrm{PoE})$ (Power of Engineering Inc., 2019). The PoE organization is a collaborative effort between the Australian Government, schools, universities, and industry and was co-founded by two woman engineering graduates as a not-for-profit organization. One of their main programs to provide outreach to women students is a fully funded, one-day event for women students in Years 9 and 10 in secondary schools across Australia. This one of PoE's most successful events aims to have students consider careers in engineering, and features practical workshops delivered by women currently working in the engineering profession and engineering student volunteers. Year 9 and 10 students participate in hands-on, small group activities to learn about applications in biomedical, civil, and aerospace engineering fields. In the global pandemic context, PoE continued to engage students and show them the impact engineers have on society through their "engineering-in-a-box" reusable classroom resource. Since the beginning of $\mathrm{PoE}$ in 2012, the organization has reached 9,450 women students (Power of Engineering, 2020).

Engineering-based activities can provide opportunities for students to think systematically, solve important technical problems, and simultaneously provide tangible contributions to our society. Typically, women are interested in, and particularly good at, design thinking, i.e. thinking about problems holistically, handling uncertainty, and developing strategies and design decisions for solving problems (Coleman et al., 2020). Collaborative and supportive women in engineering organizations, programs, and initiatives, such as the examples discussed in this chapter, benefit engineering students as well as the future of the engineering profession.

\section{Recruiting and Supporting Women (Academic) Staff}

Gender inequality in STEM industries prevents organizations from recruiting and retaining women in the STEM sector. Lack of women in STEM positions, especially in senior or leadership roles, can be detrimental to the success of any organization (National Academies of Sciences, Engineering, and Medicine, 2020; Funk \& Parker, 2018). A diverse workforce leads to more diverse and creative perspectives and provides potential role models for women students in engineering schools (ACED, 2017b; NSF, 2005). Many Australian 
universities have prioritized these issues and are participating in national programs to improve the careers of women in science-based areas. Science in Australia Gender Equity (SAGE) program, which is based on the U.K.'s Athena SWAN (Scientific Women's Academic Network) model, is one nation-wide program and it is provided with millions of dollars in support from the Australian Government. Outcomes of the SAGE program in Australian universities include improved arrangements for caregiver or parental leave, expanded on-campus childcare, and women-only recruitment processes.

The engineering education (and STEM) community in Australia continues to provide other support networks for women academic staff and hosts WIE events at conferences, symposiums, workshops, and mentoring programs for junior faculty. The WIE panel at the IEEE Teaching, Assessment and Learning for Engineering (TALE) conference brought together panelists to discuss contemporary issues for women in engineering and provide a range of actionable advice on how they can implement strategies at their own institutions (Chakraborty et al., 2018). One example, the Women in STEM Symposium (2019), was designed to facilitate collaboration and minimize duplication of effort across universities, industries, and schools. The Women in STEM Workshop for Educators (WISTEMxQ workshop, 2020) targeted educators in STEM with students in years 5-8. The WISTEMxQ workshop was in conjunction with the Australian Government programs that highlight women's STEM careers and aim to increase girls' participation in engineering. The National Committee for Women in Engineering special interest group of the professional body, EA, works to attract and retain women in engineering careers and to support women across their engineering careers (Engineers Australia, 2021). The availability and use of these support networks throughout women's academic and professional careers is a consistent approach that should help women at various stages of their careers. Panels, workshops, events, or dedicated sessions that facilitate connections with other women academic staff (and faculty and staff that are involved in the recruitment and support of women academic staff) provide opportunities to help increase persistence of women in engineering.

\section{Improving the Curriculum}

Misconceptions around the engineering profession, including what an engineer actually does, can impact the number of women undertaking engineering studies. Women pursuing engineering degrees tend to persist in a curriculum that emphasizes the social contexts of engineering practice and is delivered by a gender-balanced academic staff team. Emphasizing human-centered design and sustainable development reflects contemporary needs for all engineering graduates and can attract more women (ACED, 2017b).

Programs can adopt innovative curricula to train Australian students about issues in the societal context of engineering. For example, engineering programs should address engineering's impact on the environment and emphasize the positive influence of humanitarian engineering (ACED, 2019). Humanitarian 
engineering-focused programs attract a significantly higher percentage of female engagement in this area compared to other engineering programs (Smith et al., 2017; Lynch \& Smith, 2020). Twenty-eight universities and over 10,000 students in Australia and New Zealand participate in a humanitarian engineeringfocused design challenge for first-year students (EWB, 2020). Humanitarian Engineering degrees, courses, and experiential opportunities are currently offered at 11 universities (Lynch \& Smith, 2020). The Australian Federal Government provides financial support for mobility programs that offer opportunities for overseas study experiences in humanitarian engineering (Department of Foreign Affairs and Trading (n.d.); Smith et al., 2017). Examples of humanitarian engineering education initiatives to improve curriculum, from a standpoint of increasing women's participation in engineering, are discussed in the following sections.

\section{Engineers without Borders Australia (EWB-A)}

In this section, we will introduce Engineering Without Borders Australia (EWBA) education programs which facilitate engagement between Australian (and New Zealand) undergraduate engineering students and domestic or international community partners. EWB-A offers school outreach programs, such as the EWB University Challenge Program, Humanitarian Design Summit, Bespoke Study Tour, the Influencer Fellowship, and other research projects. The Humanitarian Design Summit is an immersive (two-week, study abroad) learning experience for students from engineering and non-engineering majors to engage in community development and apply humanitarian engineering skills and insights in countries such as Cambodia, Nepal, and Timor-Leste. The Bespoke Study Tour is similar to the Summit and allows academics to work with EWB to incorporate programs that align with their curriculum. The Influencer Fellowship is designed for finalyear students who want to help reform practice and culture in the engineering sector and support sustainable development. Influencer Fellowship recipients receive professional mentoring and training from humanitarian and development practitioners. The EWB research program brings together community organizations, universities, and research centers to identify and conduct research that benefits communities through innovative engineering and development solutions. Students' research projects with EWB are part of their formal studies and can be their final-year thesis, research, or capstone project (EWB, 2020).

Universities' collaboration with EWB-Australia promotes students' understanding and ability to create positive change within developing communitieswithin and outside of Australia - through humanitarian engineering frameworks and socio-technical solutions. Women and men are motivated to participate in humanitarian engineering initiatives (Stoakley et al., 2017) when their values align with those initiatives. In the subsection that follows, we detail the EWB University Challenge and how it provides opportunities within the curriculum to support activities that align with women in engineering value sets and reflect the social contexts of engineering application. 


\section{The EWB University Challenge}

The EWB University Challenge incorporates learning humanitarian engineering with project-based activities as part of Australian and New Zealand first-year engineering curricula (EWB, 2020). The goal of the program is to involve students in learning the practices, behaviors, ethics, and cultures of professional humanitarian engineers and to develop a professional identity as humanitarian engineers. Curricular and co-curricular activities that draw upon the EWB annual challenge provide teams of student engineers the opportunity to solve real-world problems with human dimensions. The EWB University Challenge activities are designed to comprehensively support students' professional development, as engineers, based on integrating technical, teamwork, and communication skills.

The EWB University Challenge focuses on human-centered design (HCD) and requires students to understand wider cultural implications of their engineering solutions when designing for Indigenous communities in developing countries or in a domestic context. The HCD process is a practice-based approach that prepares students for life and work, either in engineering or in other areas, such as teaching them about sustainability and how to understand user needs. The PBE approach provides learning experiences and activities that prepare students for professional roles as engineers and fosters identity development. Documenting and reflecting on the HCD process is critical to developing the skills required to be a professional engineer and to applying the real-world practices of humanitarian engineering.

The types of curricular activities included as part of the EWB University Challenge are intended to prepare women (and men) engineering graduates to undertake sustainability challenges and other global issues (Brown et al., 2016). EWB-Australia develops the annual challenge with different community partners each year, such as the United Nations High Commissioner for Refugees (UNHCR) Zambia and Live and Learn Vanuatu, to provide a design brief for engineering students to employ HCD and a strengths-based approach to community improvement. Implementation of the EWB University Challenge varies across the 28 universities that undertake the challenge annually. Various learning activities centered around the challenge encompass key pedagogical purposes that include 1) Learning in communities of practice, 2) Developing critical and decision-making capabilities, and 3) Self-directed and transformative learning for practice (EWB, 2020).

Students undertaking the challenge typically utilize an engineering design approach and follow the HCD process. One method to facilitate students in developing an engineering design approach is to have them create an e-portfolio containing documentation as part of their self-directed and transformative learning for practice as humanitarian engineers. Design artifacts within the e-portfolio can include the project scope, ideation methods (brainstorming ideas, sketches, etc.), design notebook entries, team member evaluations, peer reviews, prototypes, failure reports, and final design documentation 
(Goncher \& Devitt, 2017). The EWB University challenge culminates with a design showcase where each university is represented by the universityselected team with their final design solution for the partnering community. The showcase is a forum for student teams to interact with teams from other universities, EWB-A professionals, engineers from industry, and selected community partner representatives.

\section{A Practical Leaming Activity for Engineering Educators Developing and Delivering Socio-Technical Course Content}

In this subsection, we describe an activity that can be implemented in most engineering design and/or community engagement projects to provide women in engineering programs with curriculum opportunities that show how engineering can be put into practice. Stoakley, Brown, and Matthee (2017) found that women and men whose value sets align with humanitarian engineering are motivated to participate in humanitarian projects. The proposed activity is based on the empathize phase of the HCD process. The design phase, "empathize," focuses on listening to the user to uncover wants, needs, pain points, and desired gains. In this activity, individual students or teams consult with a professional (who can be from other professions outside of engineering, e.g. a nurse, legal professional, or barber) to learn about their occupation, their life, strengths, and opportunities. This is an opportunity for teams to familiarize themselves with professions, practice communication skills, and gain a better understanding of the early phases of the HCD process.

- Learning Activity: Developing HCD Solutions through Engineering Community Engagement.

- Goal: Apply HCD skills and knowledge to solicit and interpret information from community members. The learning outcomes for this activity include 1) Application of skills in a practice-based context (students will apply their skills and knowledge to navigate a given context), 2) Use of human-centered design principles (students will be able to utilize HCD techniques to solicit and interpret information from community members and potential end-users of their engineering design solutions), and 3) Address important issues, approaches, or considerations in human-centered design (students will be able to identify and discuss the impact of applying human-centered design principles in a given context).

\section{- Activities and Desired Outcomes}

The first step is to consult with a community member in a specific occupation/job/career to learn more about their work, their life, and strengths to elicit opportunities for potential design solutions. Participants are encouraged to take photos and notes about what they observed, heard, and/or tried while spending time with the professional/community member. The second step is to create an empathy map of the community member's needs and assets. Students will use 
information collected through their consultation in Step 1 to identify and synthesize the community member's needs.

The final step is to provide and develop engineering design solutions for the identified need(s) and resulting design opportunity identified by engaging with the community member(s). The planned evaluation strategy (see Table 11.1) for this learning activity includes suggested reflective components that require students to think about the HCD process and the application of skills related to HCD in a real context. The instructor can use Table 11.1 to help guide students in creating artifacts that document their process and facilitate their reflection on the application of skills in a practice-based context, use of human-centered design principles, and addressing important issues, approaches, and considerations in human-centered design.

The "Developing HCD Solutions through Engineering Community Engagement" activity can be implemented as part of the EWB University Challenge or any design project where students interact with a community or specific user group. The combination of interaction with community members and the reflection on the activity/experiences will help students understand how the application of HCD-related skills can benefit their studies and their long-term professional experiences that require community engagement. The reflective component, and the learning activity itself, can contribute to an improved curriculum that relates to female engineering student values sets (Stoakley, Brown, Matthee, 2017).

Table 11.1 Engineering Community Engagement Evaluation Matrix

\begin{tabular}{|c|c|c|}
\hline Learning Outcomes & Artifacts & Reflections \\
\hline $\begin{array}{l}\text { Application of skills } \\
\text { in a practice-based } \\
\text { context }\end{array}$ & $\begin{array}{l}\text { - Proposed engineering solu- } \\
\text { tion and technical require- } \\
\text { ments for the professional to } \\
\text { use in practice } \\
\text { - Photos and videos of the } \\
\text { experience } \\
\text { - Drawings/visualizations of the } \\
\text { process }\end{array}$ & $\begin{array}{l}\text { What did you observe? } \\
\text { What did you ask? } \\
\text { What can the professional } \\
\text { (person(s) of focus in the } \\
\text { challenge) try to do } \\
\text { differently? }\end{array}$ \\
\hline $\begin{array}{l}\text { Use of human-cen- } \\
\text { tered design } \\
\text { principles }\end{array}$ & 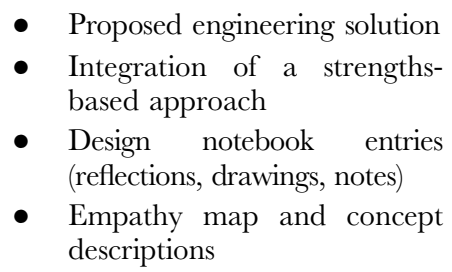 & $\begin{array}{l}\text { What different methods } \\
\text { did you use? } \\
\text { What worked well, why? } \\
\text { What didn't work well, } \\
\text { why? } \\
\text { What was challenging or } \\
\text { interesting? }\end{array}$ \\
\hline $\begin{array}{l}\text { Address important } \\
\text { issues, approaches, } \\
\text { and considerations } \\
\text { in human-centered } \\
\text { design }\end{array}$ & $\begin{array}{l}\text { - Journal-style reflections on the } \\
\text { activity and process of imple- } \\
\text { menting human-centered } \\
\text { design principles }\end{array}$ & $\begin{array}{l}\text { What would you do better } \\
\text { next time? } \\
\text { What improvements } \\
\text { would you make based on } \\
\text { what you learned? }\end{array}$ \\
\hline
\end{tabular}




\section{Conclusion}

In this chapter, we described and contextualized Australian undergraduate engineering education as it relates to increasing participation of women in engineering studies and future careers. We presented example programs and initiatives that address the needs and recommendations for action identified in contemporary reports by academia, industry/ professional organizations, and Australian Government departments. We illustrated successful university-level WIE programs that integrate undergraduate engineering students' activities with programs aimed at recruiting primary and secondary school students, provide or facilitate mentoring opportunities within the university, and connect undergraduate women engineers with industry networks and opportunities. We also highlighted examples of humanitarian engineering curricular and co-curricular experiences that promote gender diversity in engineering education.

We conclude that collaboration between stakeholders and across programs with a cohesive message will aid in getting women into engineering studies and keeping women in the profession. Barriers to participation in engineering occur at all points along women's academic and professional career pathways. No individual program or initiative, which exists to support the attraction, retention, and progression of women, can completely remove the barriers faced by women in engineering. Rather, programs and initiatives reinforced by academia, industry, and government have a significant opportunity to facilitate women along their engineering education and work pathways and have a positive impact on women's participation in engineering education and beyond.

\section{References}

Australian Academy of Science. (2019). Women in STEM decadal plan. Australian Academy of Science.

Australian Council of Engineering Deans. (2016). Position statement promoting engagement between industry and universities for improving engineering graduate capabilities and accelerating innovation. http://www.aced.edu.au/downloads/posi tion_statement_no_1.pdf

Australian Council of Engineering Deans. (2017a). Position statement embedding Aboriginal and Torres Strait Islander perspectives into the engineering curriculum. https://www.engineersaustralia.org.au/sites/default/files/resource-files/2017-09/POS ITION $\%$ 20STATEMENT $\% 20 \mathrm{No} \% 204 \% 20$ Indigenous $\% 20$ engineering $\% 20 \mathrm{DJH} \% 2$ 0v\%202\%20RWK\%20rev\%20logo\%20(002)\%20(00000002).pdf

Australian Council of Engineering Deans. (2017b). Position statement increasing the participation of women in engineering education. https://www.aced.edu.au/down loads/POSITION_STATEMENT_No_2_PromotingWomen.pdf

Australian Council of Engineering Deans. (2019). Position statement mathematics requirements for engineering education. http://www.aced.edu.au/downloads/ POSITION\%20STATEMENT\%20No\% 205\%20Mathematics\%20Requirements\% 20for\%20Engineering\%20Degrees.pdf 
Australian Council of Engineering Deans (ACED). (2018,April). Humanitarian engineering education providing an opportunity for a new generation of engineers [Position Statement]. Australian Council of Engineering Deans.

Berge, M., Silfver, E., \& Danielsson, A. (2018). In search of the new engineer: Gender, age, and social class in information about engineering education. European fournal of Engineering Education, 44, 1-16. https://doi.org/10.1080/03043797.2018.1523133

Brodie, L., \& Bullen, F. (2013, June), AAEE plenary - Engineering education: A national integrated approach. Paper presented at 2013 ASEE International Forum, Atlanta, Georgia. https:// doi.org/10.18260/1-2-17212

Brown, N. J., Price, J., Turner, J. P., \& Colley, A. (2016). 27th annual conference of the Australasian Association for Engineering Education, AAEE Lismore, NSW, Southern Cross University, 96-104.

Chakraborty, S., Ros, M., Cheng, E., Goncher, A., \& Vial, A. (2018). Panel sessionWomen in engineering networking panel. 2018 IEEE International Conference on Teaching, Assessment, and Learning for Engineering (TALE). https://doi.org/10. 1109/tale.2018.8615387.

Coleman, E., Shealy, T., Grohs, J., Godwin, A. (2020). Design thinking among firstyear and senior engineering students: A cross-sectional, national study measuring perceived ability. Fournal of Engineering Education, 109, 72-87.

Corrigan, D., \& Aikens, K. (2020). Barriers to participation in engineering and the value of interventions to improve diversity. https://cog-live.s3-ap-southeast-2.amazonaws.com/n/ 1271/2020/Jan/20/oZ3DuHs2Cklt1085UsDe.pdf

Cross, K., Miletic, M., Forin, T., Mina, M., Jain, A., Villa, E., Ingram, E. L. (2017). Panel: Influencing culture and curriculum via revolution. 2017 IEEE Frontiers in Education Conference (FIE). https://doi.org/10.1109/fie.2017.8190627.

van Driel, J. H., Vossen, T. E., Henze, I., \& and de Vries, M. J. (2018). Delivering stem education through school-industry partnerships: A focus on research and design. In STEM education: An emerging field of inquiry (pp. 31-44). https://doi.org/10. 1163/9789004391413_003.

Department of Education and Training. (2018). https://www.education.gov.au/.

Department of Education, Skills and Employment. (2020). uCube - Higher education data cube. http://highereducationstatistics.education.gov.au

Department of Foreign Affairs and Trade. (n.d.) The New Colombo plan mobility program. https://www.dfat.gov.au/people-to-people/new-colombo-plan/mobility-p rogram/Pages/mobility-Program.

Department of Industry, Science, Energy, and Resources. (n.d.) Advancing women in STEM strategy. Australian Government. https://www.industry.gov.au/data-and-p ublications/advancing-women-in-stem-strategy/snapshot-of-disparity-in-stem/womenin-stem-at-a-glance.

Education Services Australia. (2018). https://www.esa.edu.au/about/about-us.

Engineers Australia. (2020, December). Engineers Australia Accredited Programs.

Engineers Without Borders. (2020). https://www.ewb.org.au/

Fifty50. (n.d.) About. https://fifty50.org.au.

Funk, C. \& Parker, K. (2018, January 9). Women and men in STEM often at odds over workplace equity. Pew Research Center. https://www.pewresearch.org/social-trends/ 2018/01/09/women-and-men-in-stem-often-at-odds-over-workplace-equity/

Goncher, A.M., \& Devitt, J. (2017). Development of global competencies through humanitarian engineering experiences. https://researchoutput.csu.edu.au/en/p ublications/development-of-global-competencies-through-humanitarian-engineering 
Graham, R. H. 2018. The global state of the art in engineering education [Report]. https:// jwel.mit.edu/assets/document/global-state-art-engineering-education

Howard, P., \& Campbell, D. (2013). Invited Paper-Curriculum Development to meet Accreditation Requirements. 2013 ASEE International Forum Proceedings. https://doi. org/10.18260/1-2-17242.

Kaspura, A. (2019). The engineering profession: A statistical overview (13th ed.). Engineers Australia.

Lynch, E., \& Smith, J. I. (2020, June). Emergence and evolution of humanitarian engineering education in Australia. Paper presented at 2020 ASEE virtual annual conference. Virtual Online. https://doi.org/0.18260/1-2-34521

National Academies of Sciences, Engineering, and Medicine. (2020). Promising practices for addressing the underrepresentation of women in science, engineering, and medicine: Opening doors. The National Academies Press. https://doi.org/10.17226/25585.

National Committee for Women in Engineering (NCWIE). (n.d.) https://www.engineersa ustralia.org.au/Communities-And-Groups/Special-Interest-Groups/Women-In-Engin eering

National Science Foundation (NSF). (2005). The engineering workforce: Current state, issues, and recommendations.

Office of the Chief Scientist. (2016). Australia's STEM workforce: Science, technology, engineering and mathematics. http://www.chiefscientist.gov.au/wp-content/uploa ds/Australias-STEM-Workforce_April-2016_web.pdf.

Power of Engineering Inc. (2019). Inspiring the next generation about engineering. http://www.powerofengineering.org/

Power of Engineering Inc. (2020). 2020 Annual report. http://www.powerofengineering. org/.

Smith, J., Anderson, B., Brown, N., Colley, A. Stoakley, A. \& Turner, J. (2017). The rise of humanitarian engineering education in Australasia. in 28th Annual Conference of the Australasian Association for Engineering Education (AAEE), https://aaee.net.au/wp-con tent/uploads/2018/09/AAEE2017-Smith_Brown_Stoakley_et_al-Humanitarian_engi neering_education_in_australasia.pdf, p. 312.

Stoakley, A., Brown, N., \& Matthee, S. (2017). The role of a humanitarian focus in increasing gender diversity in engineering education ... In N. Huda, D. Inglis, N. Tse, \& G. Town (Eds.), 28th annual conference of the Australasian Association for Engineering Education (AAEE 2017) (pp. 438-446). Australasian Association for Engineering Education.

WISTEMxQ: Women in STEM Ambassador and Questacon Partnership. (2020). https:// womeninstem.org.au/wistemxq/

Women in Engineering and IT Symposium and Network (2019, October). https:// www.uts.edu.au/about/faculty-engineering-and-information-technology/women-en gineering-and-it/our-community-and-events/women-engineering-and-it-symposium -and-network-2019

Workplace Gender Equality Agency (WGEA, the Agency). (2021, February). https://www. wgea.gov.au/sites/default/files/documents/Gender_pay_gap_fact_sheet_Feb2020.pdf 